Z. klin. Chem. u. klin. Biochem.

7. Jg., S. 8-13, Januar 1969

\title{
Akute Barbitalwirkungen auf den Protein- und Nucleinsäurestoffwechsel der Rattenleber
}

\author{
Von H. Kröner, B. Gutenberger ${ }^{1}$ ), S. Hollmann und W. Staib \\ Aus dem Institut fïr Pbysiologische Chemie der Universität Dï̈sseldorf
}

(Eingegangen am 5. August 1968)

Es wurden kinetische Analysen von Barbitalwirkungen an der Rattenleber durchgeführt. Die Aktivität der Threonindehydratase und der Tryptophanpyrrolase sowie des Blutgerinnungsfaktors $V$ fälit primär ab, steigt wieder an und weist danach noch ein zweites Minimum auf. Entsprechend verhält sich die, über den Einbau von Leucin- $\left[1-{ }^{14} \mathrm{C}\right]$ in vivo gemessene Proteinsynthese. Auch die RNA-Synthese, gemessen über den RNA-Gehalt und über den Einbau von Orotsäure- $\left[5-{ }^{3} \mathrm{H}\right]$ in vivo, wird durch Barbital gehemmt. Hier findet sich nur ein Minimum. Der DNA-Gehalt nimmt kontinuierlich geringfügig ab. Die Analyse der Adeninnucleotide ergibt einen Anstieg des ATPGehaltes mit einem Maximum 4 Stdn. nach der Barbitalinjektion. Der Zusammenhang der beobachteten Barbitalwirkungen wird diskutiert.

\section{The effect of acute barbital loading on the protein and nucleic acid metabolism of rat liver.}

Kinetic analyses are reported on the action of barbital on rat liver. The activities of threonine dehydrase, tryptophan pyrrolase and blood coagulation factor $\mathrm{V}$ show an initial decrease, followed by an increase, then a second minimum. The same behaviour was shown by the in vivo protein synthesis, measured by the incorporation of $\left[1{ }^{14} \mathrm{C}\right]$ leucine. The synthesis of RNA, measured by the RNA concentration and the incorporation of $\left[5-{ }^{3} \mathrm{H}\right]$ orotic acid, was also inhibited by barbital, and there was only one minimum. There was a continuous small decrease in the concentration of DNA. Analysis of the adenine nucleotides showed an increase in the concentration of ATP to a maximum $4 \mathrm{hr}$. after the injection of barbital. The relationship between these effects is discussed.

Barbiturate und verschiedene andere Pharmaka verursachen eine Aktivitätszunahme mikrosomaler Enzy'me über eine gesteigerte Proteinsynthese (1). Zu den so ,,induzierbaren“ Enzymen gehört die UridindiphosphatGlucuronyltransferase (EC 2.4.1.17) und auch die nicht mikrosomale Uridindiphosphatglucose-Dehydrogenase (EC 1.1.1.22) (2). Wie HollaranN und Mitarbeiter (3) zeigen konnten, bewirkt Barbital (Veronal) bzw. Aminophenazon primär eine kurzfristige Aktivitätsabnahme dieser beiden Enzyme. Damit ergibt sich die Frage, ob diese Hemmung auch Enzyme betriff, die nicht mit dem Arzneimittelabbau in Zusammenhang gebracht werden können, ob also die Proteinsynthese der Leber generell durch Barbital primär gehemmt wird. Als Nebenbefund wird eine solche akute Hemmung der Proteinsynthese durch Nembutal in der Literatur erwähnt (4). Für Enzymuntersuchungen schienen uns Enzyme mit kurzer Halbwertszeit besonders geeignet wie die Tryptophanpyrrolase (EC 1.13.1.12) (5), die Threonindehydratase (EC 4.2.1.16) (6) und der Blutgerinnungsfaktor V (7), ein spezifisches Protein, das in der Leber synthetisiert wird. Den Einfluß von Barbital auf die gesamte Proteinsynthese der Leber haben wir zu ermitteln versucht durch Messung des Einbaus von markiertem Leucin in vivo. Da eine Proteinsynthesehemmung sekundäre Folge einer Hemmung der RNA-Synthese sein könnte, haben wir die Beeinflussung derselben durch Barbital über den Einbau von markierter Orotsäure in vivo untersucht. Um eine eventuelle Störung des Energiestoffwechsels als primäre Ursache der Barbitalwirkung zu erfassen, haben wir die Adeninnucleotide der Leber bestimmt.

1) Diese Arbeit enthält wesentliche Teile der Dissertation von B. Gutenberger (Med. Fakultät Univ. Düsseldorf 1969).
Die Versuche wurden an adrenalektomierten Tieren durchgeführt, um sicher zu stellen, daß es sich um direkte, hormonunabhängige Barbitalwirkungen handelt (8).

\section{Methodik}

Männliche Wistar-Ratten (Fa. Brünger, Bokel) 200-300 g schwer, wurden in leichter Äthernarkose von einem dorsalen Medianschnitt ausgehend doppelseitig adrenalektomiert. Bis zum Versuchsbeginn, 5-6 Tage nach der Operation, erhielten die Tiere physiologische Kochsalzlösung und Standardfutter (Fa. Höveler, Langenfeld-Immigrath).

Veronal wurde in Form des Na-Salzes, $150 \mathrm{mg} / \mathrm{kg}$ als $1,5 \mathrm{proz}$. Lösung in physiologischer Kochsalzlösung, i. p. injiziert.

$\mathrm{Zu}$ verschiedenen Zeiten nach der Veronalinjektion wurde in leichter Äthernarkose der Bauchraum eröffnet, durch Punktion der Aorta Blut entnommen, dieses 1:9 mit 3,8proz. Na-Citratlösung versetzt und das Plasma zur Bestimmung des Faktors V abzentrifugiert. Anschließend wurden Leberproben zur Beștimmung der Enzymaktivitäten der Tryptophanpyrrolase und der Threonindehydratase entnommen. Nach einmaliger Punktion und Entnahme der Gewebsproben wurden die Tiere getötet.

Die Bestimmung der Threonindebydratase erfolgte nach PIror und Peraino (6). Als Eichsubstanz für die dabei verwendete Farbreaktion nach GREENBERG ( 9 ) diente $\alpha$-Ketobuttersäure reinst der Fa. Schuchardt. Die Tryptophanpyrrolașe wurde nach KNox und Auerbach (10) bestimmt.

Die Bestimmung des Blutgerinnungsfaktors $V$ erfolgte nach dem Einphasenprinzip mit den Reagenzien und nach der Vorschrift der Fa. Behringwerke AG. Der Faktorengehalt des Normalplasmas - ein Mittelwert von 10 nicht adrenalektomierten Kontrolltieren - diente als $100 \%$-Wert. Die Beziehung ziwischen Faktorengehalt (Plasmaverdünnung) und Gerinnungszeit wurde von uns wie üblich ermittelt. $\mathrm{D}_{\mathrm{a}}$ im Normalfall bei dieser Methode nur ein Abfall des Gerinnungsfaktors zu erwarten ist, wir aber auch mit einem Anstieg über den 100\%-Wert rechnen mußten, haben wir von den Versuchstieren jeweils den 50\%-Normwert zusätzliche Plasmaverdünnung 1:1 - angesetzt. Damit sind Werte zwischen $20 \%$ und $200 \%$ direkt aus der Eichkurve ablesbar, Werte über $200 \%$ sind extrapoliert. 


\section{Merckotest ${ }^{e}$}

vollständige Reagenziensätze für medizinisch-chemische Untersuchungen

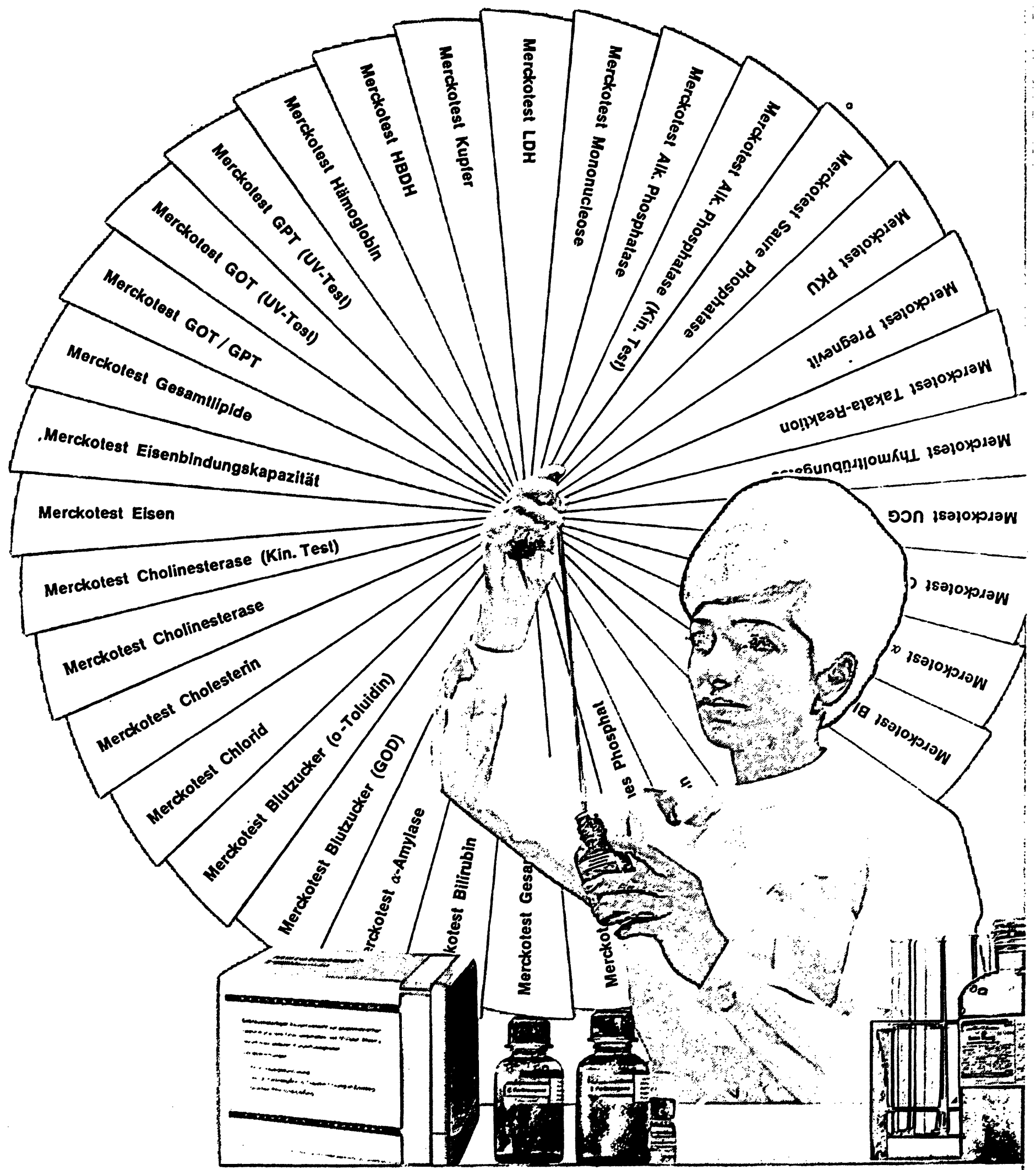

Das umfassende Sortiment

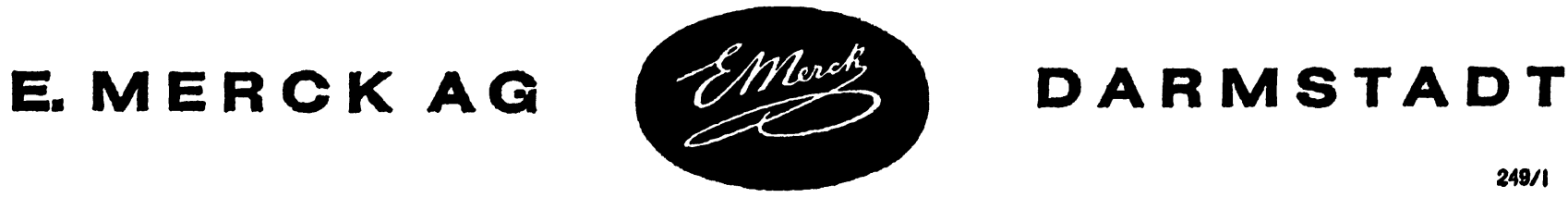


In ' ciner zwciten Versuchsscrie wurde zu verschiedenen Zeiten nach der Barbitalinjektion in leichter Athernarkose eine Leberprobe mittels Frierstopp entnommen. Daraus wurde zunächst mit cisgekühlter Perchlorsäure der Extrakt I hergestellt zur Bestimmung der Adeninnucleotide (11). Aus dem Rückstand wurden mit einer modifizierten Schmidt-Thannhauser-Methode $(12,13)$ dic Nucleinsäuren extrahiert (Schema I) Einzelheiten siehe (14).

Schema I: Extraktion der Nucleinsäuren aus Leber.

Gewebsrückstand nach Extraktion mit kalter $\mathrm{HClO}_{4}$

$$
+1 \mathrm{~N} \mathrm{NaOH}
$$$$
+\mathrm{HClO}_{4} \text { kalt }
$$

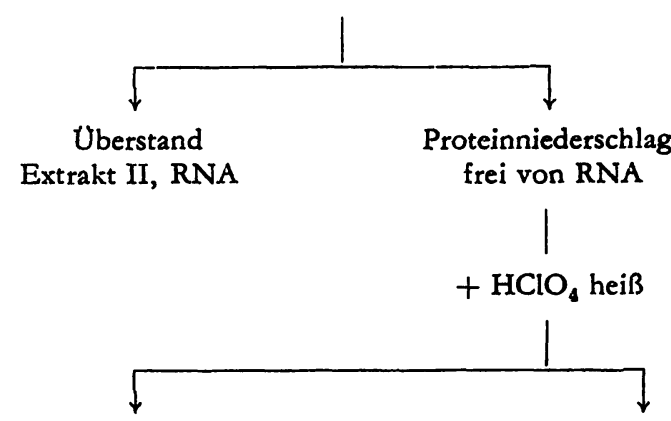

Uberstand

Niederschlag

Extrakt III, DNA

(verworfen)

Die Proteinbestimmung erfolgte mit dem Biuretreagenz nach Weichselbaum (15), Eichsubstanz war Serumalbumin vom Rind der $\mathrm{Fa}$. Behringwerke. Die RNA wurde durch Extinktionsmessung bei $260 \mathrm{~nm}$, die DNA nach Burron (16) bestimmt. Als Eichsubstanz diente für beide Bestimmungen hydrolysierte Kalbsthymus-DNA der Fa. Serva.

30 Min. vor der Tötung erhielten die Tiere dieser zweiten Versuchsserie eine intraperitoneale Injektion von Leucin- $\left[1-{ }^{14} \mathrm{C}\right]$, $20 \mu \mathrm{C} / \mathrm{kg}$ und Orotsäure-|5-3 $\mathrm{H}$ ], $60 \mu \mathrm{C} / \mathrm{kg}$. Das Leucin hatte eine spezifische Aktivität von $27,5 \mu \mathrm{C} / \mathrm{mg}$, die Orotsäure von $5000 \mathrm{mC} /$ mMol.

Die Messung der Radioaktivität erfolgte im Tri-Carb, Liquid Scintillation Counter der Fa. Packard Instruments, als Scintillationsgemisch diente Diotol (17). Quenchkorrektur erfolgte mittels externen Standards. Gemessen wurde die ${ }^{14} \mathrm{C}$-Aktivität des Leucin im RNA-freien Proteinniederschlag. Dieser wurde mit kalter Perchlorsäure nachgewaschen, in $1 \mathrm{~m} l$ Hydroxid of Hyamin ( $\mathrm{Fa}$. Röhm \& Haas) gelöst und zum Scintillationsgemisch gegeben. Die Tritium-Aktivität der Orotsäure wurde in Extrakt II gemessen, der die teilhydrolysierte RNA enthält. $0,5 \mathrm{ml}$ Extrakt II wurden mit Scintillationsgemisch versetzt. Nebeneinander haben wir die ${ }^{14} \mathrm{C}$ - und Tritium-Aktivität des Extraktes I gemessen, von dem ebenfalls $0,5 \mathrm{ml}$ mit Diotol versetzt wurden. Entsprechend der unterschiedlichen Energie der Strahlung der beiden Nuclide wurde in einem Kanal des Tri-Carb fast ausschließlich ${ }^{14} \mathrm{C}$, in einem anderen Kanal vorwiegend Tritium gemessen. Bei fehlendem oder konstantem und daher zu vernachlässigendem Quench kann über eine einfache rechnerische Korrektur die wahre ${ }^{14} \mathrm{C}$ - und Tritium-Aktivität der Proben ermittelt werden. Der Korrekturfaktor wurde in Vorversuchen ermittelt, bei denen jeweils nur ein Nuclid gegeben wurde.

\section{Ergebnisse}

Relativ kurzfristig nach dẹ Barbitalinjektion fanden wir sowohl für die untersuchten Leberenzyme als auch für den Gerinnungsfaktor $V$ eine Aktivitätsabnahme (Abb. 1). Das erste Aktivitätsminimum liegt für die Threonin-
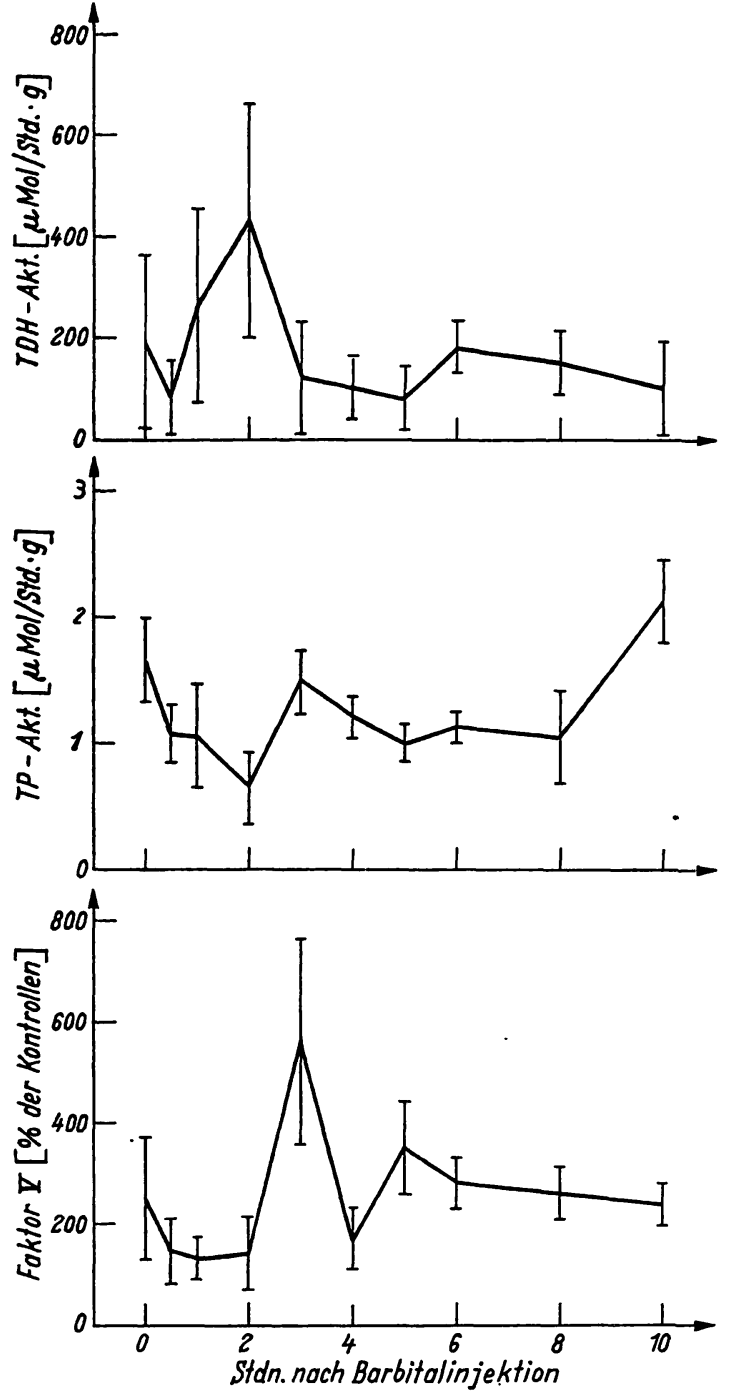

Abb. 1

Enzymaktivitäten in der Leber adrenalektomierter Ratten nach Gabe von Barbital-Na, $150 \mathrm{mg} / \mathrm{kg}$ i. p. für Threonindehydratase (TDH) und Tryptophanpyrrolase (TP) in $\mu$ Mol Substratumsatz/Std. $\cdot g$ Frischgewicht, für den Faktor $V$ in Prozent der intakten (nicht adreStandardabweichung

dehydratase 1/2 Std. nach der Barbitalinjektion, für den Faktor V 1 Std. und für die Tryptophanpyrrolase 2 Stdn. nach der Barbitalinjektion. Die primäre $\mathrm{Ab}-$ nahme ist für den Faktor $V$ schwach $(p<0,05)$ und für die Tryptophanpyrrolase deutlich $(p<0,001)$ signifikant gegenüber den unbehandelten Kontrollen (Abb. 1). Es folgt für alle drei Proteine ein signifikanter Aktivitätsanstieg, Tryptophanpyrrolase: $\mathrm{p}<0,001$, Threonindehydratase: $\mathrm{p}<0,01$, Faktor $\mathrm{V}: \mathrm{p}<0,001$. Dabei liegt das Maximum der Threonindehydratase 2 Stdn. nach Barbitalgabe $125 \%$ über den Kontrollwerten, das Maximum des Faktors V 3 Stdn. nach Barbitalgabe ebenfalls $125 \%$ über den Kontrollwerten. Nur das Maximum der Tryptophanpyrrolase-Aktivität 3 Stdn. nach der Barbitalinjektion erreicht nicht ganz den Wert der unbehandelten Kontrollen. Die Aktivität der untersuchten Enzyme fällt danach wieder ab unter den Normalwert der Kontrolltiere. Diese zweiten Minima für die Tryptophanpyrrolase und die Threonin- 
dehydratase liegen 5 Stdn. nach der Barbitalgabe und sind gegenüber dem Maximum mit $p<0,001$ (Tryptophanpyrrolase) und $p<0,01$ (Threonindehydratase) signifikant. Der Abfall des Faktors V bis zur 4. Std. ist besonders steil und hochsignifikant $(p<0,001)$. Es folgt schließlich noch ein zweiter signifikanter Aktivitätsanstieg für die Threonindehydratase $(p<0,02)$, für den Faktor $V(p<0,001)$ und für die Tryptophanpyrrolase $(p<0,001)$. Der zweite Anstieg der Tryptophanpyrrolase zwischen 8 . und 10 . Std. nach der

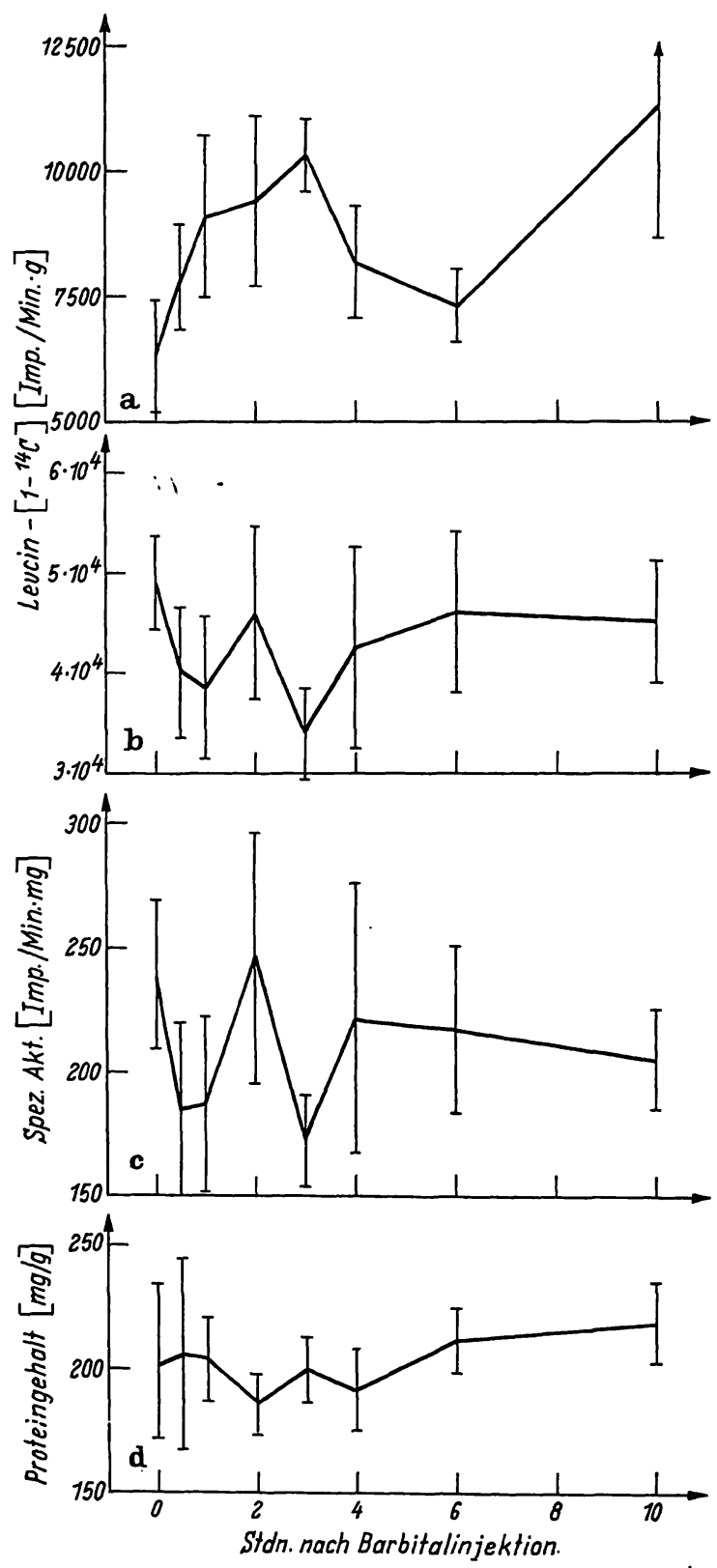

Abb. 2

Proteingehalt und Einbaurate von Leucin- $[1-14 \mathrm{C}]$ in Rattenlebern in vivo nach Gabe von Barbital- $\mathrm{Na}, 150 \mathrm{mg} / \mathrm{kg}$. Leucin [1-1'C], $20 \mu \mathrm{C} / \mathrm{kg}$ a: Aktivität von Leucin $\left[1{ }^{14} \mathrm{C}\right]$ in der säurelöslichen Fraktion, Imp./ Min./g Leber

b: Einbau von Leucin[1-“a $]$ in die Proteinfraktion, Imp./Min./g c: Spezifische ${ }^{14} \mathrm{C}$-Aktivität der Proteinfraktion, Imp./Min./mg Protein $\mathrm{d}$ : Proteingehalt der Leber in $\mathrm{mg} / \mathrm{g}$ Frischgewicht

Mittelwerte von mindestens 5 Einzelwerten \pm Standardabweichung
Barbitalinjektion erfolgt relativ spät im Vergleich zu dem Wiederanstieg der Threonindehydratase und des Plasmafaktors V nach 6 bzw. 5 Stdn. Diese beiden Proteine zeigen danach bis zur 10. Std. keine signifikanten Aktivitätsänderungen mehr.

In der ersten Std. nach Barbitalinjektion wird vermindert Leucin- $\left[{ }^{14} \mathrm{C}\right]$ in das Leberprotein eingebaut (Abb. 2). Die Einbauhemmung setzt sofort nach der Injektion ein und beträgt $24 \%$ bezogen auf Leberfrischgewicht und $22 \%$, berechnet als spezifische Aktivität.
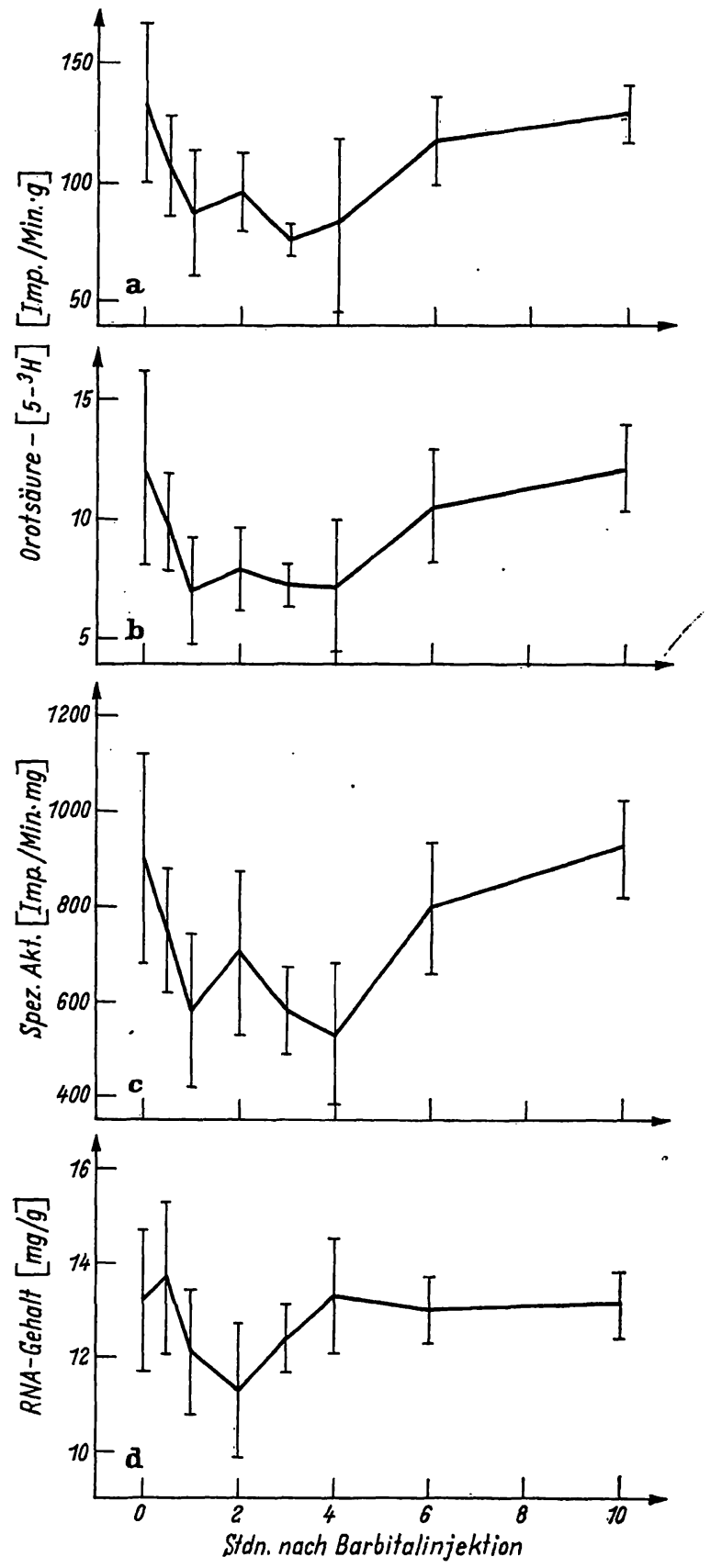

Abb. 3

RNA-Gehalt und Einbaurate von Orotsäure $\left[5-{ }^{3} \mathrm{H}\right]$ in Rattenlebern in vivo nach Gabe von Barbital-Na, $150 \mathrm{mg} / \mathrm{kg}$. Orotsäure [5-2 $\mathrm{H}], 60 \mu \mathrm{C} / \mathrm{kg}$ i. p. 30 Min. vor der Tötung

a: Einbau von Orotsäure[5-' $\mathrm{H}$ ] in die säurelösliche Fraktion, Imp./ Min./g Leber

b: Einbau von Orotsăure [5-9 $\mathrm{H}$ ] in die Leber-RNA. Im p./Min./g Leber c: Einbau von Orotsäure[5-3 $\mathrm{H}]$ in die Leber-RNA, spezifische Aktivität, Imp./Min./mg RNA

d: RNA-Gehalt der Leber in $\mathrm{mg} / \mathrm{g}$ Frischgewicht

Mittelwerte von mindestens 5 Einzelwerten \pm Standardabweichung 
Beide Werte sind statistisch signifikant $(p<0,02)$. Beim Wiederanstieg der Einbaurate zur 2. Std. nach der Barbitalgabe ist nur der auf den Proteingehalt der Leber bezogene Wert schwach signifikant $(p<0,05)$. Der Abfall der Einbaurate zu einem zweiten Minimum 3 Stdn. nach der Barbitalgabe, sowie der folgende Anstieg bis 6. Std. sind jeweils mit $\mathrm{p}<0,02$ signifikant.

Die ${ }^{14} \mathrm{C}$-Aktivität im säurelöslichen Uberstand (Extrakt I) verhält sich fast rezipprok zur ${ }^{14} \mathrm{C}$-Aktivität im Protein. Sie steigt nach einer Std. signifikant an um nahezu 50\% ( $p<0,01)$. Der Abfall der säurelöslichen ${ }^{14} \mathrm{C}$-Aktivität fällt zeitlich genau mit dem endgültigen Wiederanstieg der ${ }^{14} \mathrm{C}$-Aktivität im Protein zusammen. Er ist ebenfalls signifikant $(p<0,05)$ zwischen 4 . und 6. Std. $10 \mathrm{Stdn}$. nach der Barbitalgabe fanden wir eine unerklärliche erhöhte ${ }^{14} \mathrm{C}$-Aktivität im säurelöslichen Überstand. Die säurelösliche ${ }^{14} \mathrm{C}$-Aktivität verhielt sich dünnschichtchromatographisch in verschiedenen Systemen wie freies Leucin (13). Der Proteingehalt der Leber, bezogen auf Frischgewicht, ändert sich nach Barbital nur relativ geringfügig. Die Abnahme bis zur 2. Std. nach der Injektion beträgt $8 \%$, sie ist nicht signifikant.

Der $R N A$-Gebalt der Leber (Abb. 3) nimmt stärker ab als der Proteingehalt. Das Minimum 2 Stdn. nach der Barbitalgabe liegt um 15\% unter dem Kontrollwert $(p<0,02)$. Der Abnahme des RNA-Gehaltes geht eine verminderte Einbaurate von Tritium markierter Orotsäure in die RNA voraus. Zwischen der 30. und 60 . Min. nach Barbitalinjektion wird etwa $40 \%$ weniger Orotsäure eingebaut $(p<0,01)$ als ohne Barbital. Parallel zu dem verminderten Einbau in die RNA geht eine Abnahme der Aktivität im säurelöslichen Úberstand (Extrakt I) $(p<0,05)$. Da sich diese säurelösliche Fraktion dünnschichtchromatographisch in verschiedenen Systemen anders verhielt als Orotsäure, dürfte es sich im wesentlichen um Nucleotide handeln. Es ist also der Einbau von Orotsāure in Mononucleotide ebenfalls kurzfristig vermindert. Später, im wesentlichen 4 bis 6 . Stdn. nach der Barbitalgabe, steigt die Tritiumaktivität im säurelöslichen Überstand parallel zum Anstieg der Einbaurate in die RNA wieder an. Letzterer ist schwach signifikant $(p<0,05)$.

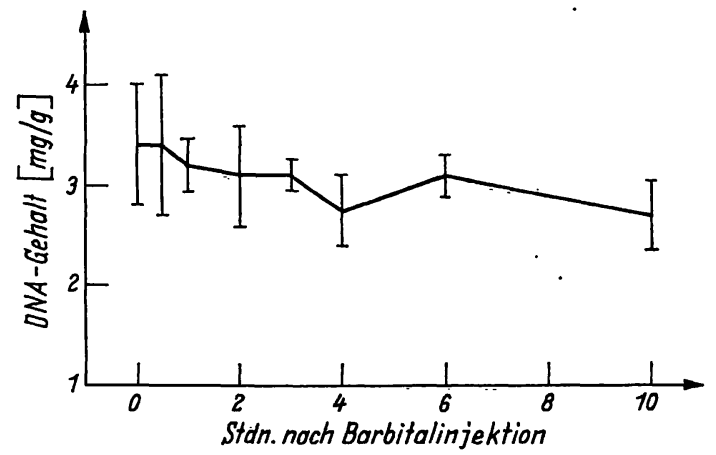

Abb. 4

DNA-Gehalt der Leber in $\mathrm{mg} / \mathrm{g}$ Frischgewicht nach Gabe von Barbital-Na, $150 \mathrm{mg} / \mathrm{kg}$, Mittelwerte von mindestens 5 Einzelwerten \pm Standardabweichung

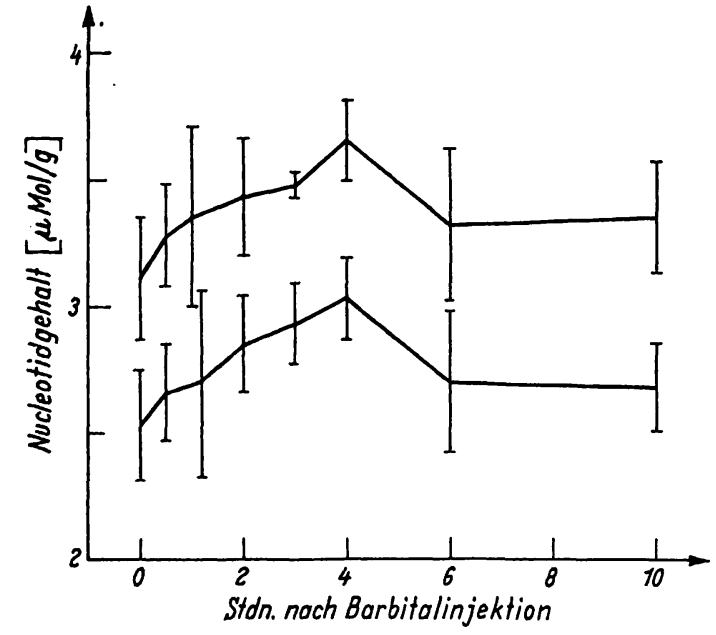

Abb. 5

Adeninnucleotide der Leber in $\mu \mathrm{Mol} / \mathrm{g}$ Frischgewicht nach Gabe von Barbital-Na, $150 \mathrm{mg} / \mathrm{kg}$. Obere Kurve: Summe der Adeninnucleotide, untere Kurve: ATP in $\mu$ Mol/g Frischgewicht. Mittelwerte von 6 Einzelwerten \pm Standardabweichung

Der DNA-Gebalt der Leber bezogen auf Feuchtgewicht (Abb. 4) nimmt nahezu kontinuierlich während der $10 \mathrm{Stdn}$. ab. Die Differenz beträgt $20 \%$, ist jedoch gegenüber dem Ausgangswert nicht statistisch signifikant. Legt man andererseits die DNA-Werte als über 10 Stdn. konstant zugrunde und bezieht darauf $z$. B. den Protein- und RNA-Gehalt, so ergibt sich für diesen im Endeffekt eine 25proz. Zunahme.

Die Bestimmung der Adeninnucleotide (Abb. 5) ergab eine absolute Zunahme des ATP-Gehaltes, der schon nach 2 Stdn. statistisch signifikant ist $(p<0,02)$. Der 3- und 4-Stunden-Wert unterscheidet sich mit $p<0,01$ von den Kontrollen. Die maximale Zunahme beträgt $+20 \%$ nach 4 Stdn. Die Gehalte an ADP und AMP verändern sich dem gegenüber kaum, so $d a ß$ auch das Verhältnis der Adeninnucleotide nur unwesentlich verschoben ist. Zwischen der 4. und der 10. Std. nach Barbitalinjektion fällt der AंTP-Gehalt signifikant ab $(p<0,01)$ und liegt dann nur noch unwesentlich über dem Niveau der Kontrollen.

\section{Diskussion}

Der Effekt einer einmaligen Barbitalinjektion auf die Leberenzyme Tryptophanpyrrolase und Threonindehydratase und den in der Leber synthetisierten Gerinnungsfaktor $\mathrm{V}$ entspricht in wesentlichen Punkten der früher beschriebenen Barbitalwirkung auf die LeberUridindiphosphatglucose-Dehydrogenase und der Aminophenazonwirkung auf die Leber-UridindiphosphatGlucuronyltransferase (3). Die Aktivität aller 5 Enzyme fällt zunächst akut $a b$, steigt danach an, weist ein zweites Minimum auf und pendelt sich danach in etwa auf das Auṣgangsniveau ein. Zum Teil recht unterschiedlich verhalten sich dagegen die Zeiträume für - Aktivitätsabnahmen und Aktivitätszunahmen. Eine wesentliche Ursache dafür dürften die unterschiedlichen Halbwertszeiten der Enzymproteine sein (5, 6, 7). 
Verglichen mit der Halbwertszeit des Gesamtleberproteins $(18,19)$ und der Plasmaproteine (20) von 2-3 Tagen handelt es sich um Enzyme mit relativ kurzer Halbwertszeit, was die Bedeutung der letzteren für die beobachteten Phänomene unterstreicht. Die zeitliche Verschiebung der Aktivitätsmaxima und Minima dürfte ferner durch die Halbwertszeit der m-RNA beeinflußt werden. Diese Halbwertszeit der m-RNA beträgt nach JoHN und MILLER (21) für Serumalbumin im Mittel 2-4 Stdn., für Leberprotein weniger als 6 Stdn. Die Halbwertszeit der m-RNA einzelner Proteine kann natürlich von diesem Mittelwert abweichen, sie beträgt $z$. B. für Fibrinogen 1,5 bis 2 Stdn. (21).

Die Tatsache, daß die zuletzt untersuchten Enzyme nicht mikrosomal sind und auch in keinem erkennbaren Zusammenhang mit dem Abbau von Arzneimitteln stehen, weist darauf hin, daß die Barbitalwirkung sehr unspezifisch ist und die gesamte Leberzelle betrifft. So konnten Holtz und Mitarbeiter (22) nachweisen, daß die cytoplasmatische DOPA-Decarboxylase durch Phenobarbital induziert wird. Gelborn (23) konnte zeigen, daß in die durch Phenobarbital stimulierte Proteinsynthese auch cytoplasmatische Proteine einbezogen sind.

Die von uns durchgeführte kinetische Analyse des gesamten Leberproteines ergibt ein dem Verhalten der Enzymaktivitäten entsprechendes Bild. Dem Abfall der Enzymaktivität entspricht hier eine verminderte Einbaurate von markiertem Leucin in das Protein. Dieser verminderte Leucineinbau beginnt sofort nach der Barbitalinjektion. In Kombination mit dem Anstieg des nicht eingebauten Leucin- $\left[{ }^{14} \mathrm{C}\right]$ fassen wir die verminderte Einbaurate als Hemmung der Proteinsynthese auf, zumal Vorgänge, die zu einem Isotopenverdünnungseffekt führen könnten, aus zeitlichen Gründen nicht in Frage kommen. Mit einer gewissen Verzögerung folgt der Synthesehemmung ein geringer, allerdings nicht signifikanter Abfall des Proteingehaltes der Leber. Das zweite Minimum des Leucin- $\left[{ }^{14} \mathrm{C}\right]-$ Einbaues möchten wir ebenfalls als Ausdruck einer gehemmten Proteinsynthese auffassen, obwohl hier ein Isotopenverdünnungseffekt nicht sicher ausgeschlossen werden kann. Allerdings spricht der Abfall des nicht eingebauten Leucin- $\left[{ }^{14} \mathrm{C}\right]$ gleichzeitig mit dem Wiederanstieg der Einbaurate für die Annahme einer zweiten Proteinsynthesehemmung.

Auch auf die RNA-Synthese der Leber übt Barbital eine Hemmwirkung aus. Der Einbau von Orotsäure in die gesamte Leber-RNA ist vermindert, allerdings parallel dazu auch der Einbau in die Nucleotidfraktion. Diese Parallelität läßt daran denken, daß die Barbitalhemmung schon auf der Stufe der Nucleotidsynthese angreift. Die Hemmung kann sich jedoch nicht auf die Nukleotidfraktion beschränken, indem eine verminderte Radioaktivität der Nucleotide bei an sich normaler RNA-Syntheserate eine Hemmung der RNASynthese vortäuschte. Der verminderte Einbau von Orotsäure- $\left[5^{-} \mathrm{H}\right]$ in die RNA muß auch Ausdruck einer
RNA-Synthesehemmung sein, da mit einer Verzögerung von etwa $1 / 2$ Std. der RNA-Gehalt der Lèber signifikant abfällt.

Es erscheint paradox, daß zunächst der RNA-Gehalt wieder ansteigt und sich erst später die Einbaurate für Orotsäure- $\left[5-{ }^{3} \mathrm{H}\right]$ in RNA- und Nucleotidfraktion normalisiert. Die RNA-Synthese kann nach der 2. Std. nicht mehr gehemmt sein, wenn der RNA-Gehalt zwischen der 2. und 4. Std. nach der Barbitalinjektion wieder ansteigt. Der verminderte Einbau von markierter Orotsäure in die RNA kann zu diesem Zeitpunkt daher nur die Folge eines Isotopenverdünnungseffektes und feerner einer verminderten Nucleotidsynthese aus der angebotenen Orotsäure-[5- $\left.{ }^{3} \mathrm{H}\right]$ sein. Das setzt einen Anstieg der Pyrimidinnucleotide voraus, der über Feedback den Einbau von Orotsäure hemmt (24) und andererseits die durch eingebaute Orotsäure-[5-3 $\left.{ }^{3} \mathrm{H}\right]$ markierten Nucleotide verdünnt. Der postulierte Anstieg der Pyrimidinnucleotide dürfte die Folge der vorausgegangenen RNA-Synthesehemmung sein. Derzeitig laufende Untersuchungen sollen diese Hypothese bestätigen. Eine wesentliche Stütze erfährt sie schon jetzt durch das Verhalten der untersuchten Adeninnucleotide. 4 Stdn. nach der Barbitalinjektion, wenn der RNA-Gehalt schon wieder angestiegen ist, die Einbaurate der Orotsäure- $\left[5-{ }^{3} \mathrm{H}\right]$ aber noch weitgehend gehemmt ist, weisen die Adeninnucleotide ein deutliches Maximum auf. Ein entsprechendes Verhalten der Pyrimidinnucleotide erscheint uns sehr wahrscheinlich, es würde die zunächst paradox erscheinenden Veränderungen im RNAStoffwechsel erklären.

Die RNA-Synthese erfährt also nur eine einmalige Hemmung, die mindestens eine, höchstens aber 2 Stdn. dauert. Wir möchten annehmen, daß die daraus resultierende Abnahme der RNA die Ursache für die Hemmung der Proteinsynthese zwischen der 2. und 3. Std. nach der Barbitalinjektion ist. Der primäre $\mathrm{Ab}-$ fall der Proteinsynthese innerhalb der ersten $30 \mathrm{Min}$. nach Barbitalinjektion liegt unseres Etachtens zeitlich zu früh, als daß er Folge der RNA-Synthesehemmung sein könnte. Zudem wäre es dann schwierig, einen Grund für den zwischenzeitlichen Anstieg der Proteinsynthese $z u$ finden.

Die Frage nach der Ursache für die primäre Hemmung der Protein- und RNA-Synthese muß zunächst noch offenbleiben. Sie liegt sicher nicht, wie aus den Werten der Adeninnucleotide ersichtlich, im Energiestoffwechsel. Das entspricht Befunden, bei denen von verschiedenen Barbitursäurederivaten Barbital (Veronal) mit Abstand die geringste Hemmwirkung auf die Zellatmung aufweist (25). Die Bedeutung der primären Hemmwirkung eines „induzierenden" Pharmakons wird durch Befunde anderer Autoren unterstrichen, die eine sekundäre "Induktionswirkung“ primär hemmender Pharmaka wie z. B. Cycloheximid und Actinomycin D nachweisen konnten $(8,26,27,28)$.

Wir danken Fräulein URSULA GNEIST für fleißige und gewissenhafte Mitarbeit bei der Durchführung der Versuche. 


\section{Literatur}

1. KATO, R., W. R. JandoRf, L. A. LOEB, T. Bex und H. V. Gelbors, Mol. Pharmacol. 2,171 (1966). - 2. HolusenN S. und O. Touster, Biochim. biophysica Acta Amsterdam 62, 338 (1962). 3. Holmanasx, S. und J. Neubaur, Hoppe-Seyler's Z. physiol. Chem. 348, 877 (1967). - 4. Hofert, J. F. und R. K. Boutwel, Arch. Biochem. Biophysics 103, 338 (1963). - 5. Scriske, R. T., E. IV. SWrentey und C. M. Berrn, Biochem. biophys. Res. Commun. 15, 214 (1964). - 6. Prrot, H. C. und C. Peraino, J. biol. Chemistry 239, 1783 (1964). - 7. Sснов;, R. und H. Südноғ, Biochemische Befunde in der Differentialdiagnose innerer Krankheiten, Georg Thieme Verlag Stuttgart (1965). - 8. Jondorf, W. R. und D. C. Srrox, Biochem. biophys. Res. Commun. 22, 644 (1966). - 9. Greenberg, D. M., in Methods in Enzymology, Edit. S. P. Colowick und N. O. Kaplan, Academic Press New York, London (1962). - 10. Kvox, W. E. und V. H. Auerbach, J. biol. Chemiscry 214, 307 (1955). - 11. KRöNer, H. und W. StarB, Hoppe-Serler's Z. physiol. Chem. 348, 575 (1967). - 12 Hutchrson, W. C., E. D. Dowsre und H. N. MuNro, Biochim. biophysica Acta Amsterdam 55, 561 (1962). - 13. FLECK, A. und
H.N. MuNro, Biochim. biophysica Acta Amsterdam 55,571 (1962). - 14. KRöner, H. und W. Staib, Acta Endoct. K'hrn 59, 193 (1968). - 15. Weichserbaus, T. E., Amer. J. Clin. Path. 16, 40 (1946). - 16. Burtox, K., Biochem. J. 62, 315 (1956). - 17. HerBERG, R. J., Analyt. Chem. 32, 42 (1960). - 18. Swick, R. W., J. biol. Chemistry 231, 751 (1958). - 19. NikLAs, A., E. Qundid, W. Maurer und H. Netes, Biochem. Zschr. 330, 1 (1958). 20. Friedberg, F., H. TArver und D. M. Greenterg, J. biol. Chemistry 173, 355 (1948). - 21. JoHs, D. W. and L. L. M GLLER, J. biol. Chemistry 241, 4817 (1966). - 22. PALM, D., C. ERIZERHOFF und P. Horrz, Naunjn-Schmiedebergs Arch. Pharmak. 258, 352 (1967). - 23. GelBors, H. N., Drugs and Proteinsynthesis Expl. Med. Surg. Supp!. Issue 1965, 85. - 24. Stadrasas, E. R., Advances in Enzymol. N. Y., 28, 41 (1966). - 25. SсноLz, R., F. SChWARZ und Th. Bücher, diese Z. 4, 179 (1966). - 26. FralA S., Science 157, 159 (1967). - 27. Roses, F., P. N. RAINA, R. J. Mrumollavd und CF. A. Nrchol, Science Washington 176, 661 (1964). - 28. MacKntosh, F. R. und EvgeNe Bell, Biochem. biophys. Res. Commun. 27, 425 (1967).

Prof. Dr. S. Hollmann 4000 Düsseldorf 1

Wizzelstr. 111. 